\title{
Myxomycetes of the Caramoan Islands and an update on the species found in the Bicol Peninsula, Philippines
}

\author{
Sittie Aisha B. Macabago*1, Nikki Heherson A. Dagamac ${ }^{2}$, Thomas Edison E. Dela Cruz ${ }^{3}$, \\ Steven L. Stephenson ${ }^{1}$
}

\begin{abstract}
The main objective of this study was to characterize the assemblages of myxomycetes on isolated Philippine islands through a correlational study using geographical and ecological distance in the Caramoan Islands, including an updated checklist of the myxomycetes of the Bicol Peninsula. Four islands of varying sizes and distances from each other, but all within relatively close proximity to the mainland of the Bicol Peninsula, were surveyed. A combination of traditional and more contemporary ecological tools was used to analyze diversity indices among and between the islands. Among the four islands, Matukad Island recorded the highest species richness (46.8) and taxonomic diversity index (2.6), while ranking next to Lahos island in terms of species diversity (7.9). Pairwise comparisons using community similarity indices and clustering analysis consistently showed that Lahos and Matukad are the most similar to each other, while also being closer to one another but situated farthest from the mainland. On the other hand, the two smallest islands, which were also closest to each other and to the mainland, grouped together using clustering analysis but recorded the lowest pairwise percentage similarity value. The ecological patterns in this study appear to follow the unified neutral theory of biodiversity and biogeography more than the insular biogeography theory. In addition, this study added 16 new morphospecies to the list of myxomycetes known from the Bicol Peninsula, which brings the total to 73, including one new record for the country [Lamproderma arcyrioides (Sommerf.) Rostaf.]
\end{abstract}

Keywords: slime molds, insular, biodiversity, paleotropics, unified netural theory

\section{Introduction}

Studies on Philippine myxomycetes- a group of eukaryotic fruiting amoebozoans- include species listings and lately incorporated more information on associations with certain ecological phenomena. In the last decade, myxomycete research has been conducted in various parts of the country such as Bohol (Macabago et al. 2017), Palawan (Pecundo et al. 2017),

\footnotetext{
${ }^{1}$ Department of Biological Sciences, J. William Fulbright College of Arts \& Sciences, University of Arkansas, Fayetteville, Arkansas 72701, USA

2 Institute of Botany and Landscape Ecology, University of Greifswald, Soldmannstr. 15, 17489, Greifswald, Germany

${ }^{3}$ Department of Biological Sciences, College of Science, University of Santo Tomas, España Blvd. 1008 Manila, Philippines

*Corresponding email: sbmacaba@uark.edu

Date Submitted: 11 July 2020

Date Accepted: 03 November 2020
}

parts of Mindoro (Dagamac et al. 2015a) and Negros (Alfaro et al. 2015), Lubang Islands (Macabago et al. 2016, 2012), the Hundred Islands in Pangasinan (Kuhn et al. 2013, dela Cruz et al. 2011), and the Polilio Islands in Quezon (Viray et al. 2014). For the present study, myxomycetes were collected from the four of the islands of the Caramoan island group which is comprised of more than 20 inhabited and uninhabited islands facing the Pacific Ocean (Fig. 1). These islands have a type II climate which is characterized as having no distinct dry season with maximum rainy period from November to April associated with the northeast monsoon (Basconcillo et al. 2017). The islands belong to the municipality of Caramoan in the province of Camarines Sur that lies on the mountainous Bicol Peninsula (Fig. 6) in the southeastern part of Luzon Island.

The major objective of the study herein was to conduct a rapid survey of the myxomycetes associated with forest floor debris in limestone forests. The main query was to determine if it was possible to relate geographical distances to differences in the assemblages of myxomycetes, their distribution and their diversity. 


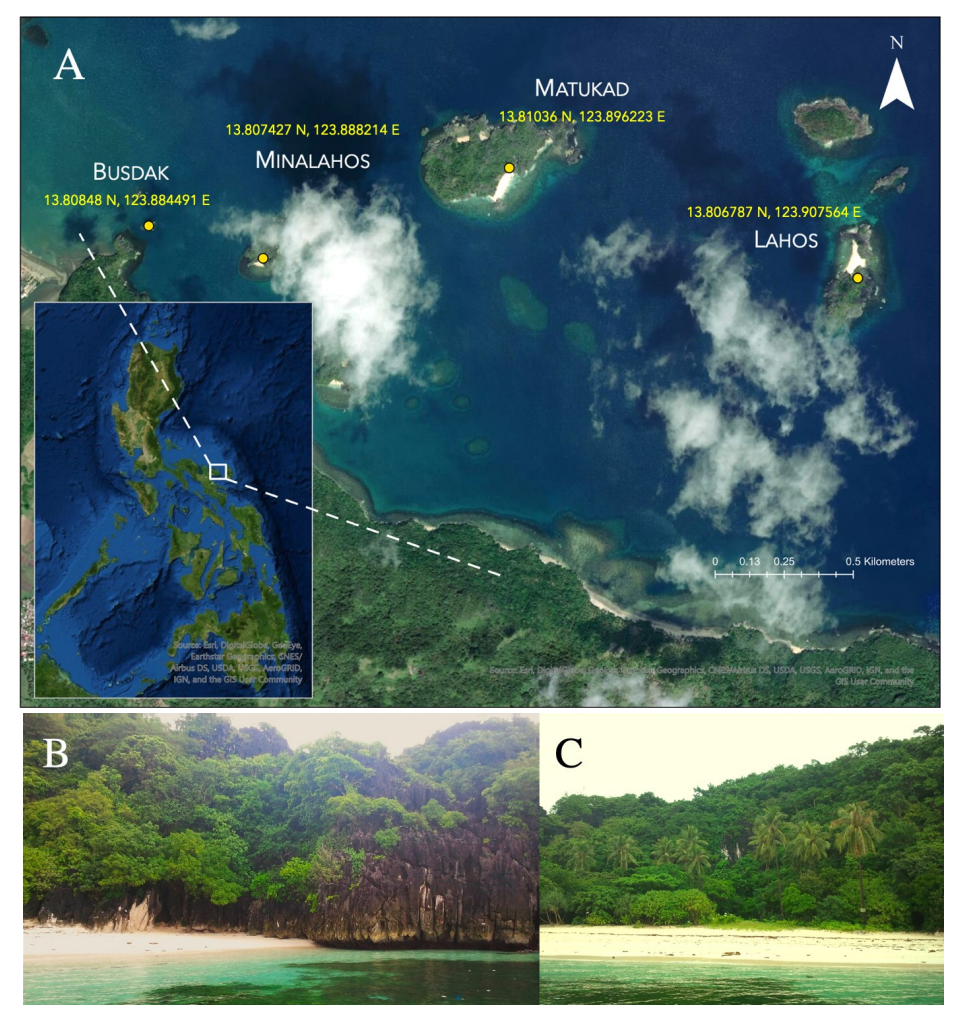

Figure 1. (A) Map of the collecting sites on the Caramoan Islands in the Philippines, showing the four selected islands marked with yellow dots. The inset on the lower left provides a map of the Philippines. (B, C) Some images of the island collection sites. Map generated using ArcGIS Pro utilizing the satellite imagery map settings.

The second part of this research aimed to provide an update to the myxomycetes of the Bicol Peninsula following the study of Dagamac et al. (2017) and add to the records of Philippine myxomycetes (Dagamac \& dela Cruz 2015, 2019).

\section{Materials and Methods}

Study area, collection protocols, setup of moist chamber cultures, and determination of myxomycetes: The samples collected for this study were obtained in 2013 from four islands/ islets of the Caramoan island group (Fig. 1), which is located on the eastern part of the archipelago opposite the Pacific Ocean. During the collection some tree species and other vegetation were spotted such as narra (Pterocarpus indicus Willd.), molave (Vitex sp.), Ipil (Intsia bijuga (Colebr.) Kuntze), and other dipterocarp trees, bamboos, and some shrubs, grasses, and mangroves in some of the beach forests. Some of these plants were also noted in a study by Balete et al. (2013) in the central and eastern portion of the Bicol Peninsula within mainland Caramoan. A combination of mostly dry and a few damp ground leaf litter (GL, 57) and twigs (TW, 83) were randomly collected along the coastal forests and woodlands from selectively accessed islands of varying sizes that were all characterized by the presence of limestone (Fig. 1, Table 1). There were no evident layers of litter on the microsites. Field specimens that developed under normal conditions were not collected because field collections are only available under field fruiting conditions suitable for myxomycetes, but the moist chamber culture approach was effective regardless of recent conditions in the study sites. All samples were air-dried at the Research Center for the Natural and Applied Sciences of the University of Santo Tomas in Manila for several weeks until there was no evidence of moisture on either the samples or the bags. These samples were then sent to the Department of Biological Sciences, University of Arkansas for processing and observation. Necessary permits from the United States Department of Agriculture (USDA) were obtained by one of the coauthors (SLS) prior to transport of substrata. A total of 140 samples were used to prepare moist chamber cultures following the protocol described by Stephenson and Stempen (1994). Overall taxonomic treatment followed Martin \& Alexopoulos (1969), with consideration of taxonomic changes made since then, using the morphological species concept by noting characteristics of the fruiting body and spore morphologies. Nomenclature followed the information system of Eumycetozoa (Lado 2005-2020).

Exhaustiveness of the survey: The software program EstimateS (Version 9.1, Colwell 2013, 100 randomizations) was used to construct species accumulation curves (SAC) to evaluate the completeness of our survey for (1) each of the study sites that were differentiated in terms of relative island size and distances among each other, and (2) the pooled dataset from all four study sites using a species-record input file. The results of the Chao 1 estimator, an estimator for target richness for individual-based data such that one record of a species in a certain culture is considered as one individual (sensu Stephenson 1988), were then used to calculate the percentage exhaustiveness by dividing the actual number of species recorded by the mean number of species expected as estimated by the Chao 1 estimator.

Analysis of myxomycete assemblages: To examine the dataset obtained from the records of myxomycetes appearing in the moist chamber cultures, various software and abundancebased species data were used for the evaluation of species richness, diversity, and degree of composition. Here, a moist chamber positive for a particular species of myxomycetes is considered as one collection or record.

The relative abundance of each species was obtained by dividing the total number of collections for each species of 
Table 1. Summary of data for the different islands (I-IV) within Caramoan group of islands, Camarines Sur showing the approximate sizes of islands, numbers of taxa, records, the values for species richness according to Chaol-bc estimator and species diversity according to Simpson's inverse index computed in SpadeR, and the values for the taxonomic diversity index (TDI) of each site.

\begin{tabular}{lccccccc}
\hline \multicolumn{1}{c}{ Locality } & $\begin{array}{c}\text { Island } \\
\text { size (m) }\end{array}$ & Records & $\begin{array}{c}\text { Taxa } \\
\text { found }\end{array}$ & Genera & TDI & $\begin{array}{c}\text { Species } \\
\text { Richness }\end{array}$ & $\begin{array}{c}\text { Species } \\
\text { Diversity }\end{array}$ \\
\hline Caramoan Islands & - & 201 & 38 & 14 & 2.7 & 83.1 & 10.2 \\
\hline Lahos (I) & $415 \times 190$ & 64 & 22 & 9 & 2.4 & 43.7 & 11.1 \\
Matukad (II) & $560 \times 320$ & 96 & 26 & 10 & 2.6 & 46.8 & 7.9 \\
Minalahos (III) & $350 \times 140$ & 18 & 10 & 7 & 1.4 & 14.7 & 6.8 \\
Busdak (IV) & $60 \times 37$ & 23 & 11 & 6 & 1.8 & 19.9 & 3.9 \\
\hline
\end{tabular}

myxomycetes by the total number of myxomycetes collected (Stephenson et al. 1993). The values were then translated to an abundance index described by Stephenson et al. (1993), for which species $<0.5 \%$ of the total number of collections are defined as rare; species $>0.5 \%$ but $<1.5 \%$ of the total number of collections defined as occasional; species $>1.5 \%$ but $<3 \%$ of the total number of collections defined as common; and species $>3 \%$ of the total number of collections defined as abundant.

To show the distribution of myxomycetes collected among and the density in each island a heat map was constructed using the software ArcGIS Pro, where a sparse to high density is represented by a range of cool to warm color schemes, respectively, such that the warmer the color in an area the more myxomycete occurrences were recorded.

Pairwise comparisons of myxomycete assemblages were carried out using Sorensen's coefficient of community (CC) and percentage similarity (PS) indices as described by Stephenson (1989). The coefficient of community (CC) index is based on the presence or absence of species in the two communities being compared. In contrast, the percentage similarity (PS) index considers not only the presence or absence of a species but also its relative abundance. The CC and PS values ranged from 0 to 1 . The higher the value, the more similar the communities are in terms of their species composition and abundance. In order to check if there is a correlation between geographic and ecological distances (using PS and CC values), a statistical test using the Mantel test (Hood 2010) was conducted.

The Taxonomic Diversity Index (TDI), which is also known as the $\mathrm{S} / \mathrm{G}$ ratio, was calculated by obtaining the ratio of the number of species to the number of genera. The value of this ratio was inversely proportional to the taxonomic diversity (Stephenson et al. 1993), where the lower ratio indicates a more diverse biota.

The online software Species-Richness Prediction and Diversity Estimation with R (SpadeR) (Chao et al. 2016) was used to generate the maximum likelihood estimator for the more intuitive Inverse Simpson index, which is a heterogeneous measure of species diversity that accounts for both the species richness and evenness, and Chao 1-bc estimator, a biascorrected form of Chao 1, for species richness. In addition, to visualize the patterns of species composition in the different islands, a clustering analysis was performed based on the BrayCurtis dissimilarities of myxomycete abundance records in the $\mathrm{R}$ environment.

\section{Results and Discussion}

The myxomycetes identified from fruiting bodies obtained from moist chamber cultures accounted for a total of 38 different morphospecies. Approximately $76 \%$ of the moist chamber cultures produced fruiting bodies after 12 weeks of observation, with ground leaf litter (86\%) being more productive than twigs (69\%). Among the islands, Matukad Island (II) yielded the highest productivity (92\%), followed by Lahos (I) Island (79\%), Busdak (IV) Island (72\%), and Minalahos (III) Island (42\%).

The entire study area showed $46 \%$ survey exhaustiveness using EstimateS (Colwell 2013). This value is lower than that of Palawan (92\%, Pecundo et al. 2017) and Lubang Island (96\%, Macabago et al. 2016), albeit comparable to studies that have been carried out in Mindoro (47\%, Dagamac et al. 2015), in Bohol (56\%, Macabago et al. 2017), and in other parts of Bicol Peninsula (58\%, Dagamac et al. 2017). The specific survey completeness for each island in Caramoan ranged from 50-68\% (Fig. 2), where Lahos recorded the lowest and Minalahos the highest. The actual and expected numbers of taxa found are shown on Table 1.

Among the 38 morphospecies identified, six were found to be abundant, while nine were common, and six were occasional. Seventeen rare species not included in Fig. 3 were all singletons from three islands (I-III). These were eight species from Lahos 
Table 2. Community similarity using percentage similarity (PS) and Sorensen's coefficient of community (CC) indices and the approximate distances between two islands.

\begin{tabular}{lccc}
\hline \multicolumn{1}{c}{ Sites } & $\begin{array}{c}\text { Approximate } \\
\text { distance (m) }\end{array}$ & $\begin{array}{c}\text { Percentage } \\
\text { Similarity (PS) }\end{array}$ & $\begin{array}{c}\text { Coefficient } \\
\text { of Community }(\boldsymbol{C C})\end{array}$ \\
\hline Lahos vs. Matukad & 1300 & $17.9 \%$ & 0.50 \\
Lahos vs. Minalahos & 2100 & $5.5 \%$ & 0.31 \\
Lahos vs. Busdak & 2500 & $7.5 \%$ & 0.42 \\
Matukad vs. Minalahos & 900 & $7.0 \%$ & 0.39 \\
Matukad vs. Busdak & 1250 & $9.5 \%$ & 0.49 \\
Minalahos vs. Busdak & 420 & $4.5 \%$ & 0.48 \\
\hline
\end{tabular}

Island (I): Badhamia utricularis, Diachea leucopodia, D. splendens, D. subsessilis, Didymium nigripes, Perichaena microspora, and Physarum cinereum; seven species from Matukad Island (II): Badhamia macrocarpa, Badhamia sp., Dictydiaethalium plumbeum, Didymium minus, Lamproderma arcyrioides, Physarum didermoides, and P. echinosporum; and two species from Minalahos Island (III): Comatricha nigra and Diderma effusum. The two collections only identified to the genus level (Badhamia sp. and Physarum sp.) had materials that were too poorly developed to identify beyond the level of species, but they were clearly different from any other species recorded in the same genus. Of the 17 singletons, nine were not recorded from mainland Bicol (see Dagamac et al. 2017 and Table 3).

The majority of the myxomycetes were found in microhabitats collected from Matukad as shown by the heat map on Figure 4. Heat maps illustrate the relative density of points or data, in this case a record of a collection, on a map as a dynamic visualization employing a scheme typically composed of gradually varying colors from cool-to-hot to indicate low-tohigh density values, respectively. The heat map shows that Matukad had the richest and most abundant collection of myxomycetes (96) as indicated by the bright yellow center inside a red ring within a thin, blue circle, and was followed by Lahos, then Busdak, and Minalahos, with the smallest number of collections as shown by a faint red center inside a diffused blue ring. The trend in the ranking of the number of collections followed the same pattern as the highest number of different taxa found on each island, computed species richness, and taxonomic diversity (Table 1). A point to consider is that the larger islands showed more records of myxomycetes, which could be correlated to the number of samples collected in each island. It is also noteworthy that the farther islands (Matukad and Lahos) from the mainland revealed the higher occurrence density.

In terms of TDI, Table 1 shows that the highest value was recorded in Minalahos (1.4) and the lowest was in Matukad (2.6), which means that although there was a higher number of morphospecies (26) found on Matukad, the variety of species on Minalahos (10) and the other two islands (Lahos with 22 and Busdak with 11) were distributed among more genera. It is clear, though, from the study that proximity of the islands to each other did not necessarily show similar number of species as also observed in the islands surveyed in the Hundred Islands,

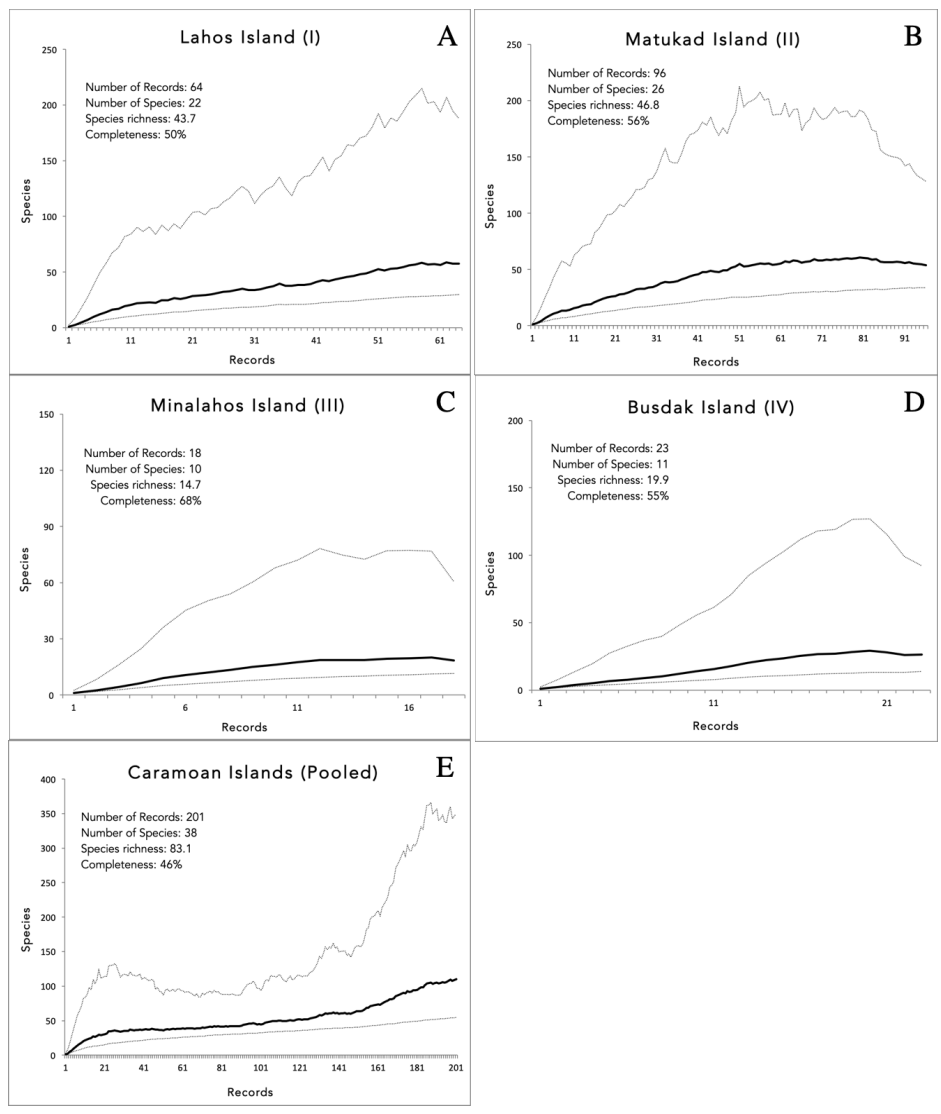

Figure 2. Species Accumulation Curves (SAC) for each of the four islands/islets (A-D) and for the pooled data set in Caramoan Islands (E). 
Table 3. Updated list of the myxomycetes of Bicol Peninsula following the initial report of Dagamac et al. (2017) and including the 16 new morphospecies (marked by *) from this study for the Bicol Peninsula with the new record for the peninsula and the country as marked by **. "+" signifies a synonym of Hemitrichia pardina (Minakata) Ing; and “++” signifies a synonym of Stemonitis fusca var. nigrescens (Rex) Torrend.

\section{Myxomycetes of the Bicol Peninsula}

Arcyria cinerea (Bull.) Pers.

Arcyria cinerea var. digitata Schwein.

Arcyria cinerea, dwarf form (Bull.) Pers.

Arcyria cinerea, yellow form (Bull.) Pers.

Arcyria denudata (L.) Wettst.

Arcyria globosa Schwein.

Arcyria incarnata (Pers.) Pers.

Arcyria insignis Kalchbr. \& Cooke

Badhamia affinis Rostaf.

Badhamia macrocarpa (Ces.) Rostaf. *

Badhamia utricularis (Bull.) Berk. *

Ceratiomyxa fruticulosa var. fruticulosa (Müll.) T. Macbr.

Clastoderma debaryanum A. Blytt

Collaria arcyrionema (Rostaf.) Nann.-Bremek. ex Ing

Comatricha fragilis Meylan

Comatricha laxa Rostaf. *

Comatricha nigra (Pers. ex J.F. Gmel.) Schroet.

Comatricha pulchella (C. Bab. \& Berk.) Rostaf.

Comatricha tenerrima (M.A. Curtis) G. Lister

Craterium leucocephalum (Pers.) Ditmar

Cribraria microcarpa (Schrad.) Pers.

Cribraria violacea $\mathrm{Rex}$

Diachea bulbillosa (Berk. \& Broome) Lister ex Penzig

Diachea leucopodia (Bull.) Rostaf.

Diachea splendens Peck *

Diachea subsessilis Peck *

Dictydiaethalium plumbeum (Schumach.) Rostaf. *

Diderma effusum (Schwein.) Morgan

Diderma hemisphaericum (Bull.) Hornem

Didymium anellus Morgan *

Didymium floccosum G.W. Martin, K.S. Thind \& Rehill

Didymium iridis (Ditmar) Fr. *

Didymium minus (Lister) Morgan *

Didymium nigripes (Link) Fr.

Didymium ochroideum G. Lister *

Didymium squamulosum (Alb. \& Schwein.) Fr. (Alb. \& Schwein.) Fr.

Didymium verrucosporum Welden
Fuligo cinerea (Schwein.) Morgan *

Hemitrichia calyculata (Speg.) M.L. Farr

Hemitrichia serpula (Scop.) Rostaf.

Lamproderma arcyrioides (Sommerf.) Rostaf. **

Lamproderma scintillans (Berk. \& Broome) Morgan

Lycogala exiguum Morgan

Perichaena chrysosperma (Currey) Lister

Perichaena depressa Libert

Perichaena dictyonema Rammeloo

Perichaena microspora Penz. \& Lister*

Perichaena minor var. pardina (Minakata) Hagelst +

Perichaena pedata (Lister \& G. Lister) G. Lister

Perichaena vermicularis (Schwein.) Rostaf.

Physarum album (Nees) Fr.

Physarum bivalve Pers.

Physarum cinereum (Batsch) Pers.

Physarum crateriforme Petch *

Physarum compressum Alb. \& Schwein.

Physarum decipiens M.A. Curtis

Physarum didermoides (Pers.) Rostaf.

Physarum echinosporum Lister

Physarum globuliferum (Bull.) Pers.

Physarum gyrosum Rostaf. *

Physarum melleum (Berk. \& Broome) Massee

Physarum cf. oblatum T. Macbr.

Physarum pezizoideum (Jungh.) Pavill. \& Lagerh.

Physarum pulcherrimum Berk. \& Ravenel in Berk.

Physarum pusillum (Berk. \& M.A. Curtis) G. Lister

Physarum stellatum (Massee) G.W. Martin

Physarum straminipes Lister *

Physarum superbum Hagelst.

Physarum tenerum Rex

Stemonaria fuscoides Nann.-Bremek. \& Y. Yamam.

Stemonitis flavogenita Jahn

Stemonitis fusca Roth ++

Stemonitis pallida Wingate 


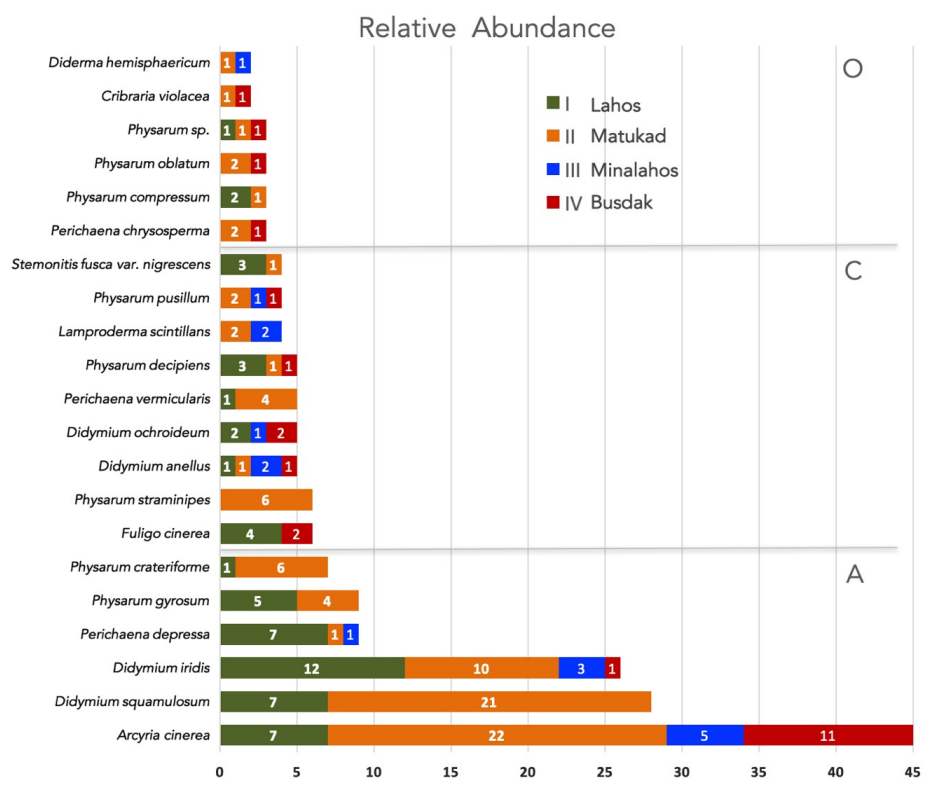

Figure 3. Relative abundance of myxomycete morphospecies collected in Caramoan Islands showing the abundant (A), common (C), and occasional $(\mathrm{O})$ species. Seventeen species were found to be rare and were not shown on the figure.

Pangasinan (dela Cruz et al. 2011). It should be emphasized that this study only utilized morphological data assessment, and so the interpretation of the results has been conducted with caution considering that our survey is solely based on the fruiting propensity of the myxomycetes.

The $\alpha$ diversity in each collecting site was calculated using Chao 1-bc and Simpson's diversity indices (Table 1). Species richness was measured using the Chao 1-bc estimator as it is the bias-corrected form of the lower bound of species richness estimator referred to as Chao 1 (Colwell \& Coddington 1994). Chao and Chiu (2016) expressed that it seems statistically impossible to get a good estimate of species richness when there are many undetectable species in a highly diverse collection. They elaborated that compared to a seemingly uncertain point estimate, an accurate lower bound for species richness is more practical to use. As such, this lower bound of undetected species richness, in terms of the numbers of singletons and doubletons (Chao 1984; 1987), was intuitively used in this study. Among the four islands, Lahos was found to be the most species diverse (11.1) and the second most species rich (43.7) next to Matukad. Consistently Minalahos and Busdak exhibited the two least species diverse and species rich islands. If we will use this observation in reference to proximity with results showing different patterns of species composition and species diversity for studies in islands conducted so far in the Philippines, these seem to defy the insular biogeography model. Perhaps, the capability of long-distance dispersal among myxomycetes possibly holds true as was also implied in another insular habitat study in Bohol (Macabago et al 2017). The only thing that still seems not clearly showcased is how capable these sporeforming organisms (like myxomycetes) are to disperse. This topic is in itself an interesting field for myxomycete ecology.

Ecological distances among the four islands were examined using clustering analysis and pairwise comparisons using community similarity indices. The Bray-Curtis index of dissimilarity using species abundance records in the $R$ environment indicated that the assemblages of myxomycetes were more similar for Lahos and Matukad, and for Minalahos and Busdak (Fig. 5) in a pairwise manner. This was somewhat supported by the community similarity indices for percentage similarity (PS) and Sorensen's coefficient of community (CC), as shown in Table 2. An interesting observation was that Minalahos and Busdak were closest to each other $(420 \mathrm{~m})$ and also the two smallest islands; however, the PS was recorded to be the lowest $(4.5 \%)$ pairwise between the islands. Lahos and Matukad, the two largest islands and relatively close to each other (see Table 2), consistently recorded the highest community similarity for both PS and CC values. Such pattern of $\beta$ diversity on adjacent collection sites had been also observed in forest patches with different degrees of disturbances in the Philippines (Bernardo et al., 2018) and in Vietnam (Redeña-Santos et al., 2018). However, to further ascertain the relationship of geographical distances with species composition among collection sites, Mantel test was performed. Mantel test analysis returned a positive correlation coefficient for both geographic

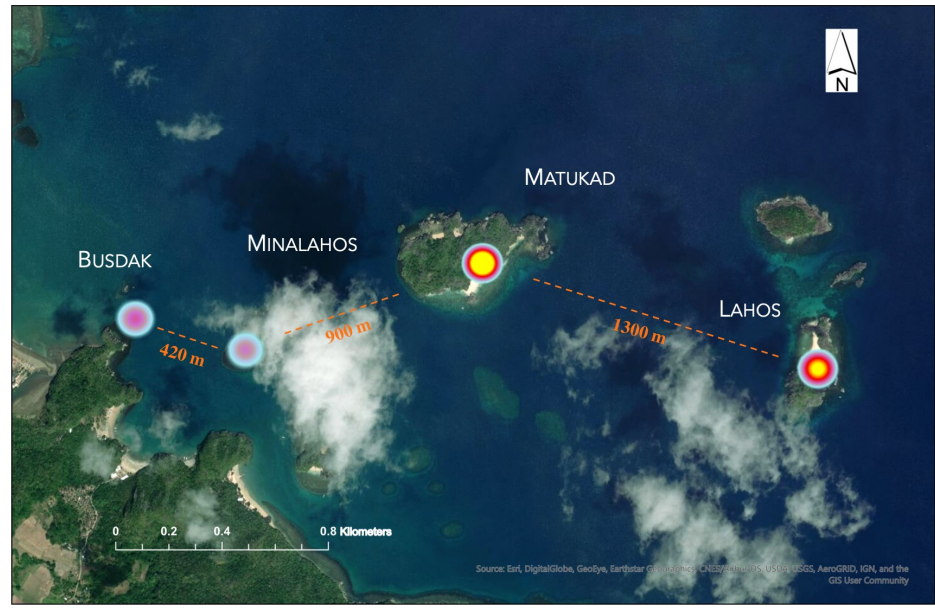

Figure 4. Density of myxomycete collections found in Caramoan group of islands showing the most records in Matukad as illustrated by the huge radius of yellow center within a red ring, followed by Lahos, Busdak, and Minalahos (faintest red core within a washed blue ring), respectively. Map generated using ArcGIS Pro utilizing the satellite imagery map settings. 
and CC distances (0.001) and geographic and PS distances (0.996) within the $95 \%$ confidence interval obtained for 999 permutations. From a statistical point of view these indicated the absence of correlation between geographic and ecological distances. If geographic proximity does not dictate the ecological similarities of these insular environments, then some other factors may play a more important role. However, without evidence on the roles of other factors, such as substrates or vegetation types, differences in species diversity and composition, that would be another speculation.

A more likely explanation seems to fit the unified neutral theory of biodiversity and biogeography (Hubbell 2001), which is essentially a hypothesis aiming to explain the diversity and relative abundance of species in communities by implying that biodiversity arises due to random birth and death events, species turnover due to local extinction and migration, and large-scale changes due to speciation, dispersal, and global extinction (Jetschke 2002). This theory essentially states that complex ecological interactions and characteristics happen, but every individual of each species in an area is per capita equivalent in a trophic community, therefore assuming neutrality. Accordingly, the island or insular biogeography theory (MacArthur \& Wilson 1967), which is commonly used to explain patterns of ecological communities on islands, cannot be applied to this current study using myxomycetes. The theory suggests that species richness in an undisturbed insular habitat is shaped by migration and extinction, such that the movements of individuals into and out of the population are affected by the distance of an island from a source of colonists, typically a

\section{Caramoan Islands}

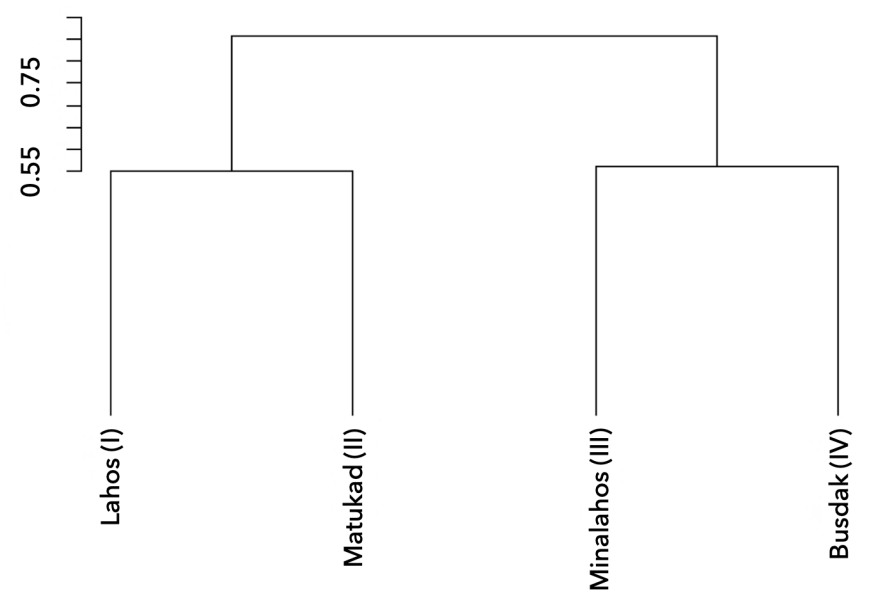

Figure 5. Clustering analysis based on Bray-Curtis dissimilarities of myxomycetes showing that the two largest islands (Lahos and Matukad) and the two smallest islands (Minalahos and Busdak) were more similar to each other.

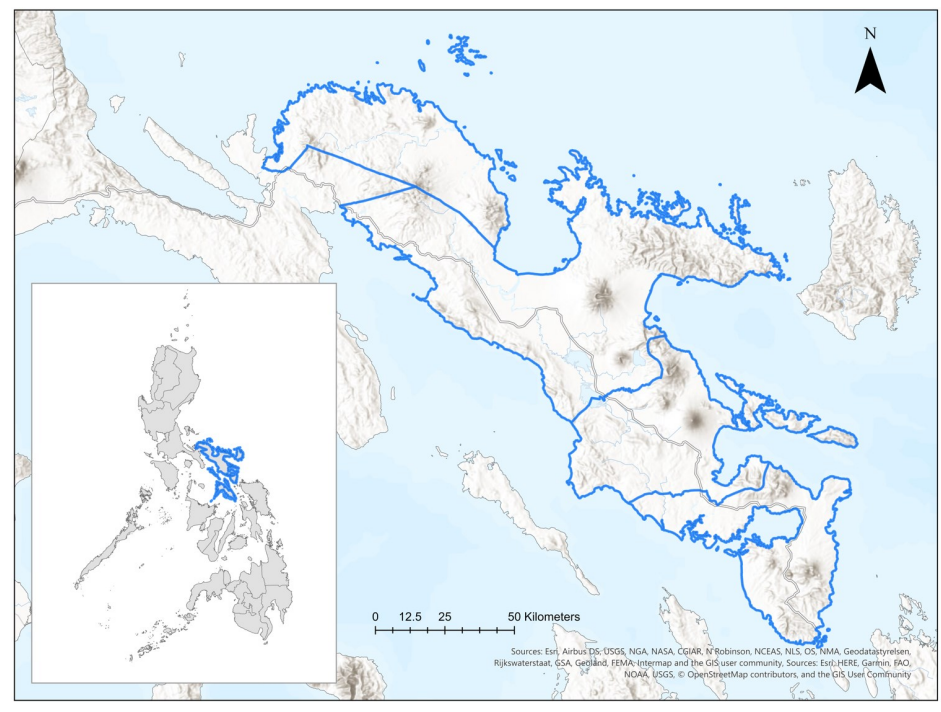

Figure 6. Map of the Bicol Peninsula as marked by the blue lines. The inset shows the Philippine map, where the entire Bicol region including the Bicol Peninsula is also delimited by blue lines.

larger mainland, although it can also be other islands. Furthermore, the rate of extinction is affected by island size, such that bigger islands offer higher variety of habitats, and therefore reduces the probability of extinction due to chance. Differences in habitats also increase the number of species that will be successful after immigration, therefore achieving equilibrium in the end. Following this logic, more isolated islands like Matukad and Lahos are less likely to receive immigrants (in this case spores or other forms of myxomycetes that could potentially survive and thrive). This could be explained with the assumption that from the main source, two islands of similar sizes but have different distances will have different species richness. The island that is closer to the source island is intuitively going to receive higher random dispersion hence, higher richness (and therefore likely higher species diversity) in comparison to an island that is farther from the source like Matukad and Lahos. This is obviously not the case for this study such that the two least species diverse and species rich islands (Minalahos and Busdak) are the nearest to the mainland. Moreover, based on the principle that two equidistant islands from the main island but with different sizes will also affect the random dispersion pattern, the smaller islands can only accommodate limited species in comparison to a larger landscape given that it satisfies the condition of neutrality. The unified neutral theory shows the value of dispersal limitation, speciation, and ecological drift in the natural world and therefore presents models for evaluating the role of natural selection and adaptation in general. Interestingly, this observed pattern can be augmented using metadata from myxomycetes studies conducted in many other islands in the Philippines. 
The Bicol peninsula constitutes four provinces (Camarines Norte, Camarines Sur, Albay, and Sorsogon) covering about 12, $070 \mathrm{~km}^{2}$ in the eastern part of the Philippines (Fig. 6). A rapid assessment of myxomycetes in the peninsula conducted by Dagamac et al. (2017) recorded 57 morphotaxa of myxomycetes collected from seven sites within the four provinces.

The present study added new records of myxomycetes to the province of Camarines Sur, which geographically and politically includes the Caramoan group of islands, and one new record for the country. Among the 38 morphospecies of myxomycetes recorded, 16 were new to the Bicol peninsula excluding two morphotaxa that were only identified to the genus level and Stemonitis fusca var. nigrescens which is a synonym of Stemonitis fusca. These are Badhamia macrocarpa, B. utricularis, Comatricha laxa, Diachea splendens, $D$. subsessilis, Dictydiaethalium plumbeum, Didymium anellus, $D$. iridis, D. minus, D. ochroideum, Fuligo cinerea, Lamproderma arcyrioides, Perichaena microspora, Physarum crateriforme, $P$. gyrosum, and $P$. straminipes (Table 3 ). Twenty morphospecies were shared with the mainland. This now brings the updated records of myxomycetes for the Bicol peninsula to 73 (Table 3), collected from 11 sites encompassing the study of Dagamac et al. (2017) and the present study. The species Lamproderma arcyrioides is a new record for the country, which now also brings the total number of records to 162 for the Philippines.

\section{Conclusions and Recommendations}

The Philippines, due to its archipelagic nature, is an ideal model to test different island biogeographic hypotheses for myxomycetes. Surprisingly at the small-scale shown in this study, it seems that myxomycetes follows the unified neutral theory of biodiversity and biogeography model instead of the insular biogeography theory. Long-term studies involving diversity studies of myxomycetes from other widespread remote islands in the Philippines would be exciting future directives to explore and disentangle biogeographic patterns of slime molds in the context of island biogeography.

\section{Acknowledgments}

SABM would like to thank the Fulbright Program and the Philippine-American Educational Foundation for the privilege to pursue a $\mathrm{PhD}$ in Biological Sciences through the Foreign Fulbright Scholarship, and the Slime Mold Project at the University of Arkansas for co-funding the research.

\section{Literature Cited}

Alfaro, J.R.D., D.L.I.M. Alcayde, J.B. Agbulos, N.H.A. Dagamac \& T.E.E. dela Cruz, 2015. The occurrence of myxomycetes from a lowland montane forest and agricultural plantations of Negros Occidental, Western Visayas, Philippines. FineFocus, 01: 07-20.

Balete, D.S., L.R. Heaney, P.A. Alviola, \& E.A. Rickart, 2013. Diversity and distribution of small mammals in the Bicol Volcanic Belt of southern Luzon Island, Philippines. National Museum of the Philippines: Journal of Natural History, 1: 61-86.

Basconcillo, J., G. Duran, A. Francisco, R. Abastillas, F. Hilario, E. Juanillo, A. Solis, A. Lucero \& S. L. Maratas, 2017. Evaluation of spatial interpolation techniques for operational climate monitoring in the Philippines. Scientific Online Letters on the Atmosphere, 13: 114-119.

Bernardo, J.L.M., J.L.Q. Arioder, K.J. Almadrones-Reyes \& N.H.A. Dagamac, 2018. Myxomycetes communities occurring in fragmented forest patches in two municipalities of Laguna, Philippines. Community Ecology, 19: 289-299.

Chao, A., 1984. Nonparametric estimation of the number of classes in a population. Scandinavian Journal of Statistics, 11: 265-270.

Chao, A., 1987. Estimating the population size for capturerecapture data with unequal catchability. Biometrics, 43: 783-791.

Chao, A. \& C. H. Chiu, 2016. Species richness: estimation and comparison. In: Balakrishnan, N., T. Colton, B. Everitt B, W. Piegorsch, F. Ruggeri, J. Teugels, (eds.), Wiley StatsRef: Statistics Reference Online. John Wiley \& Sons, Hoboken, NJ. pp. 1-26.

Chao, A., K.H. Ma, T.C. Hsieh \& C.H. Chiu, 2015. Online

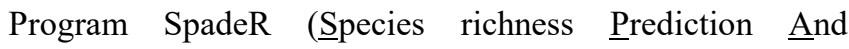
Diversity Estimation in $\underline{\mathrm{R}}$ ). Program and User's Guide published at http://chao.stat.nthu.edu.tw/wordpress/ software_download/.

Colwell, R.K., 2013. EstimateS: Statistical estimation of species richness and shared species from samples. Version 7. User's Guide and application; http://purl.oclc.org/estimates.

Colwell, R.K. \& J.A. Coddington, 1994. Estimating terrestrial biodiversity through extrapolation. Philosophical Transactions of the Royal Society of London, Series B, 345: 101-118.

Dagamac, N.H.A. \& T.E.E. dela Cruz, 2015. Myxomycete research in the Philippines: Updates and opportunities. Mycosphere, 6: 784-795.

Dagamac, N.H.A. \& T.E.E. dela Cruz, 2019. The Philippine slime molds after Dogma's 1975 list-How far have we 
been? Philippine Journal of Systematic Biology, 13: 58-65.

Dagamac, N.H.A., M.A.D. Rea-Maminta, N.S. Batungbacal, S.H. Jung, C.R.T. Bulang, A.G.R. Cayago \& T.E.E. dela Cruz, 2015a. Diversity of plasmodial slime molds (Myxomycetes) on coastal, mountain, and community forests of Puerto Galera, Oriental Mindoro, Philippines. Journal of Asia-Pacific Biodiversity, 8: 322-329.

Dagamac, N.H.A., M.A.D. Rea-Maminta \& T.E.E. dela Cruz, 2015b. Plasmodial slime molds of a tropical karst forest, Quezon National Park, Philippines. Pacific Science, 69: 411-422.

Dagamac, N.H.A., T.E.E. dela Cruz, M.A.D. ReaMaminta, J.V. Aril- dela Cruz \& M. Schnittler, 2017. Rapid assessment of myxomycete diversity in Bicol Peninsula. Nova Hedwigia, 104: 31-46.

Dela Cruz, T. E. E., R.V. Kuhn, A.O.M. Javier, C.P. Rodillas, C.M. Parra, L.H.M. Corpuz \& R. D. McHugh, 2011.

Occurrence and distribution of plasmodial myxomycetes in Hundred Islands National Park, Pangasinan, Philippines. Acta Manilana, 59: 65-74.

Hood, G.M., 2010. PopTools version 3.2.5. Available on the internet [http://www.poptools.org (accessed July 1, 2020).

Hubbell, S.P., 2001. The unified neutral theory of biodiversity and biogeography. Monographs in Population Biology, Volume 32. Princeton University Press, Princeton, NJ.

Jetschke, G., 2002. The Unified Neutral Theory of Biodiversity and Biogeography. Ecology, 83(6): 1771-1772.

Kuhn, R.V., A.O.M. Javier, C.P. Rodillas, C.M. Parra, L.H.M. Corpuz, A.T. Buaya \& T.E.E. dela Cruz, 2013. Diversity of plasmodial myxomycetes from Anda Island, Pangasinan, Philippines. Biotropia, 20: 1-9.

Lado, C., 2005-2020. An online nomenclatural information system of Eumycetozoa. Real Jardín Botánico, CSIC. Madrid, Spain. http://www.nomen.eumycetozoa.com.

Macabago, S.A.B., T.E.E. dela Cruz \& S.L. Stephenson, 2012. First records of myxomycetes from Lubang Island, Occidental Mindoro, Philippines. Sydowia, 64: 109-118.

Macabago, S.A.B., N.H.A. Dagamac, T.E.E. dela Cruz \& S.L. Stephenson, 2017. Implications of the role of dispersal on the occurrence of litter-inhabiting myxomycetes in different vegetation types after a disturbance: a case study in Bohol Islands, Philippines. Nova Hedwigia, 104 (1-3): 221-236.

Macabago, S.A.B., S.L. Stephenson \& T.E.E. dela Cruz, 2016. Diversity and distribution of myxomycetes in coastal and mountain forests of Lubang Island, Occidental Mindoro, Philippines. Mycosphere, 7(1): 18-29.

MacArthur, R.H. \& E.O. Wilson, 1967. The Theory of Island Biogeography. Princeton University Press, Princeton, $N J$.

Martin, G.W. \& C.J. Alexopoulos, 1969. The Myxomycetes.
University of Iowa Press, Iowa City.

Pecundo, M.H., N.H.A. Dagamac, S.L. Stephenson \& T.E.E. dela Cruz, 2017. First myxomycete survey in the limestone forest of Puerto Princesa Subterranean River National Park, Palawan, Philippines. Nova Hedwigia, 104 (1-3): 129-141.

Redeña-Santos, J.C., D.V. Thao, M. Schnittler \& N.H.A. Dagamac, 2018. The first report of composition and occurrence of myxomycetes assemblages in protected and unprotected plantation forest: a comparative study in Thai Nguyen City, northern Vietnam. Plant Ecology and Evolution, 151: 231-240.

Stephenson, S.L., 1988. Distribution and ecology of myxomycetes in temperate forests. I. Patterns of occurrence in the upland forests of southwestern Virginia. Canadian Journal of Botany, 66: 2187-2207.

Stephenson, S.L., I. Kalyanasundaram \& T. Lakhanpal, 1993. A comparative biogeographical study of myxomycetes in the mid-Appalachians of eastern North America and two regions of India. Journal of Biogeography, 20: 645-657.

Stephenson, S.L. \& H. Stempen, 1994. Myxomycetes A Handbook of Slime Molds. Timber Press Inc., USA.

Viray, A.T., D.D.S. Rotap, L.L. Migraso, N.C.I. Sibbaluca, E.C.V. Escobar, A.T. Buaya \& T.E.E. dela Cruz, 2014. Occurrence and diversity of myxomycetes (slime molds) in Polillo Island, Quezon Province, Philippines. Acta Manilana, 62: 9-17. 